\title{
THE COMPARISON OF TRUST DEVELOPMENT IN VIRTUAL AND FACE-TO-FACE COLLABORATIVE LEARNING GROUPS
}

\author{
Dr. Meltem Huri BATURAY \\ ORCID: 0000-0003-2402-6275 \\ Department of Basic English, School of Foreign Languages \\ Atilim University \\ Ankara, Turkey \\ Dr. Sacip TOKER \\ ORCID: 0000-0003-1437-6642 \\ Information Systems Engineering Department, School of Engineering \\ Atilim University \\ Ankara, Turkey
}

Received: 15/04/2018 Accepted: 25/02/2019

\begin{abstract}
The study investigates the effect of delivery types of (virtual and face-to-face) collaborative learning environments on the development of trust among group members in a graduate course. For this aim, a quasi-experimental, non-equivalent group comparison was used. It comprised a total of 64 participants 21 in the face-to-face group, and 43 in the virtual group. Study participants were comprised of students registered in a course entitled 'Web-based Education: Principles of Design and Implementation' in the spring semester as part of either a virtual or traditional face-to-face graduate program in Information Systems at an institute of higher education in Turkey in 2010. Trust levels were measured at two different occasions, namely in the beginning and end of the semester, for both study groups. The participants completed a web-based course material design project as a collaborative group activity. The results indicate that trust increases over time among virtual participants, but declines among face-to-face participants. While levels of trust among virtual course participants are lower than those of face-to-face course participants in the beginning of the semester, trust levels of virtual participants surpass those of faceto-face participants by the end of the semester. This study demonstrates that trust can develop in virtual learning environments. The initial level of trust should be taken into consideration by instructors or managers before forming groups.
\end{abstract}

Keywords: Trust, face-to-face communication, e-learning, collaboration, virtual groups, collaborative learning, quasi-experimental.

\section{INTRODUCTION}

Trust is acknowledged to play an important role for the flourishing of collaborative relations both in real life and in cyberspace (Gerdes, 2010). Both in virtual or traditional communities, the main purpose of participation is expected to be sharing information; in contrast, in an educational environment there are pre-defined activities which must be completed by participants or students under certain goals or objectives. In an educational environment, the major purpose is learning and sometimes collaborative activities are used to enhance learning outcomes by taking advantage of information sharing. For this reason, from trust development respect, there might be certain distinctions between collaborative and individual learning activities. Also, the situation may additionally change in a virtual mode. 
In a collaborative learning environment, the outcomes of groupwork and group-member satisfaction are affected by numerous factors. These include the cognitive, affective and psycho-motor skills of the members comprising a group. The positive feelings of group members tend to trigger motivation, leading to successful group accomplishments. For instance, trust can motivate individuals to complete a task as a group while a lack of trust can have the opposite effect. For this reason, trust is one of the factors which have a greatest effect on what group members are able to accomplish. By consolidating and extending existing research on trust, particularly with regard to virtual groups and collaborative learning environments, this study aimed to identify and explore the key factors affecting the development of trust within collaborative learning groups. In the study the word 'group' was preferred to be used instead of the word 'team' to define the participants who came together to work on a collaborative project for the purpose of completing one of the course requirements.

\section{Collaborative Learning Groups}

Williams, Duray \& Reddy (2006) define collaborative learning as a groupwork with peers seeing themselves as a source of authority and knowledge. These groups are self-managed and communicate their decisions to the instructor. Vygotsky (1978) believed that peer interaction, which takes place more in collaborative learning groups, leads to individual cognitive development and knowledge acquisition. It is suggested in the literature that collaborative learning group work results in deeper learning and understanding based on learners' involvement in a process of knowledge construction through discussion, debate and argumentation with others (Fransen, Kirschner \& Erkens, 2011). Existence of positive cooperation in these groups promotes intergroup interaction where group members encourage and facilitate other's capability to learn and achieve the group goals (Tseng, 2008). Similarly, Sangin, Molinari, Nussli and Dillenbourg (2010) underline that the effectiveness of collaborative learning relies on the quality of social interaction during collaboration. However, members should be convinced that every other group member endeavors to contribute to group work and that are no 'free riders' (Salomon \& Globerson, 1989).

Tseng (2008) emphasizes that groups working in collaboration construct knowledge while interacting. For a successful group work, members should respect other's comments and doubts, clarify misconceptions with proof and incorporate other member's contributions. Supporting this Crowe et al. (2017) state that trust plays an important role in peer-assisted learning. Although it is the ideal case, it is often not that easy to create a trustful, supportive, communicative atmosphere in groups and a consensus among the members (Tseng, 2008) particularly, in computer-supported collaborative learning environments (Jannsen, Erkens $\&$ Kirschner, 2010). This necessitates mutual information exchange and existence of a high degree of trust among collaboratively working group members. Successful collaborative learning requires both cognitive processes such as discussion, reasoning, reflection, critical thinking etc. and social processes such as developing positive affective relationships, trust, feelings of group cohesiveness etc. (Phielix, Prins, Kirschner, Erkens \& Jaspers, 2010).

\section{Development of Trust among Collaborative Learning Group Members}

Presence, development and survival of trust is so vital for group performance that its effect on group outcomes has been extensively examined in the literature (Stacey, 2002; Liu, Magjuka \& Lee, 2008; Mitchell \& Zigurs, 2009; Van Gennip, Segers \& Tillema, 2010; Fransen, Kirschner \& Erkens, 2011). Mutual trust, and sense of community (Fransen Weinberger, \& Kirschner, 2013; Leroy, Rittner, Johnson, Gerteis, \& Miller, 2017) are defined to be as key factors to successful collaboration. In fact, building up mutual trust improves learnerlearner interaction (De Meo, Messina, Rosaci, \& Sarné, 2017) or vice-versa. Various studies have found trust to enhance collaboration among group members (Serva \& Fuller, 2004); to influence group effectiveness through its impact on problem-solving, decision-making and communication within groups (Kiffin-Petersen, 2004); and to affect knowledge-sharing within groups (Staples \& Webster, 2008). However, establishing trust has been defined as one of a set of challenges faced by virtual groups (Ocker \& Fjermestad, 2008). In fact, both virtual and face-to-face groups have similar difficulties in developing and manipulating trust.

Trust development is not only the antecedent of a successful collaborative work but it is also a consequence. It is reported that trust develops during the course of effective collaborative groupwork but not in isolation, 
within continuous interaction, communication, repeated interpersonal exchange and cooperation (Wilson, Straus \& McEvily, 2006; Crossman \& Lee-Kelley, 2004). Besides, similar to 'real life', trust among group members develops with sincerity, effort and the dedication of group members. Social exchange theory asserts that interpersonal trust is positively associated with the amount of sharing. Both providers and requestors of information need to feel that the other party is sincere in order to be sure that not only is the information received from others accurate and helpful, but that information provided to others will be used appropriately. Without trust, this process does not progress; i.e., there is no social exchange (Staples \& Webster, 2008).

\section{Virtual Groupwork and Trust Building}

With recent advances in technology, traditional face-to-face groupwork has moved virtual as a result of widespread use of Internet technology in learning environments. Establishing trust has been singled out as one of the key challenges faced by virtual groups (Coppola, Hiltz \& Rotter, 2004). Virtual team trust has been defined as "the overall willingness of virtual team members to rely on one another that results from the aggregate of potential trust dimensions achieved through socio-emotional and task processes and supported by technological capabilities" (Mitchell \& Zigurs, 2009: p. 72). Virtual groups require high levels of trust if they are to succeed. West and Wallace (1988) explain that when group members feel others to be supportive rather than threatening - which points to the level of trust - they are more likely to communicate, which leads to increases in information-sharing and idea-exchange, and, in turn, increases in the number of new ideas developed.

It is apparent that the development of trust and the amount of expertise- and knowledge-sharing have a mutually affect on one another. Cheng, Nolan and Macaulay (2013) found that the development of trust in virtual groups, however, did not follow a standard pattern and influenced in fluctuations and complexities. Besides, in a temporal virtual group, there is no luxury and sufficient time to devote on trust building (Panteli \& Duncan, 2004). In a short project life-cycle, it is critical to develop trust quickly and remain it until the project is finalized. The durability of virtual groups is dependent on commitment and personal trust relationships which may be easily hindered due to the absence of face to face communication (Nandhakumar \& Baskerville, 2006).

To recap, trust is one of the most prominent factors for successful virtual collaboration (Leroy et al., 2017), and it is suggested in the literature that the effect of socio-emotional processes such as trust should be examined in a collaborative learning environment (Isohätälä, Järvenoja, \& Järvelä, 2017). It is obvious that there is a need for further studies investigating trust development in such environments. The purpose of the current study is to investigate the effect of delivery types of (virtual and face-to-face) collaborative learning environments on the development of trust among group members in a graduate course.

\section{METHOD}

This study investigated the degree to which levels of trust among group members are affected by performing tasks as a group and type of instruction delivery (face-to-face vs. virtual). The study was designed as a quasi-experimental, non-equivalent group comparison study - a type of study design commonly used when random assignment of study participants is not possible (Johnson \& Christensen, 2008). Trust levels were measured at two different occasions, namely in the beginning and end of the semester, for both study groups.

The following research questions were investigated:

1. Do groupwork activities affect trust among group members from the beginning to the end of the semester?

2. Does course-delivery mode (virtual or face-to-face) affect trust among group members?

3. Does trust change among group members over from the beginning to the end of the semester depend on course-delivery mode?

4. (As a follow-up, if any significant differences are found with regard to the first three questions), which components of trust - ability or benevolence/integrity of group members - can account for these differences? 


\section{Study Participants}

Study participants were comprised of students registered in a course entitled 'Web-based Education: Principles of Design and Implementation' at spring semester as part of either a virtual or traditional face-toface graduate program in Information Systems at an institute of higher education in Turkey in 2010. The students registered for the course in both modes of delivery were voluntary participants of the study. Thus, the method of 'Convenience Sampling' was applied for the identifications of study participants. Fraenkel and Wallen (2000) defined Convenience Sample as 'a group of individuals who (conveniently) are available for study. The course was offered by the same instructor (one of the authors of the study) following the same syllabus. Acceptance into the graduate program was based on the same criteria for both groups (virtual or face-to-face) of students.

A total of 64 students participated in the study. Students were grouped according to mode of course delivery; accordingly, 43 students (86\% male, 14\% female) were in Virtual Group and 21 students (67\% male, 7\% female) were in the Face-to-face Group. Demographic information about the participants are given in Table 1.

Table 1. Demographics of the Participants

\begin{tabular}{|c|c|c|c|}
\hline Mode of Delivery & Participants & $\mathrm{N}$ & $\%$ \\
\hline \multirow{7}{*}{ Virtual (n:43) } & Gender & & \\
\hline & Female & 6 & 14 \\
\hline & Male & 37 & 86 \\
\hline & Occupation & & \\
\hline & Engineering & 24 & 56 \\
\hline & Government Officials, Technician, Military Personnel, Teachers & 13 & 30 \\
\hline & Other & 6 & 14 \\
\hline \multirow{7}{*}{ Face-to-Face (n:21) } & Gender & & \\
\hline & Female & 7 & 33 \\
\hline & Male & 14 & 67 \\
\hline & Occupation & & \\
\hline & Engineering & 13 & 62 \\
\hline & Teachers & 5 & 24 \\
\hline & Nurses, Administrators \& Other & 3 & 14 \\
\hline
\end{tabular}

Students in Virtual Group had not met prior to the course and not allowed to communicate with each other until the beginning of the course in order to increase the quality of the study results. Students in the Faceto-face Group may or may not have known each other from previous courses.

The word 'group' was preferred to be used instead of the word 'team' to define the participants who came together to work on a collaborative project for the purpose of completing one of the course requirements. Thus, these individuals were not exposed to any prior training on how to behave in a team and how to exercise some social skills (effective communication, conflict resolution, time management, celebrating success, critical thinking and pair feedback, etc.) but they were just clarified about what was expected from them.

\section{Procedure}

In the beginning of the semester, both face-to-face and virtual group students were informed by the instructor about group projects to be completed as a course requirement. With the instructor's guidance, all students in both Virtual (Experimental Group) and Face-to-face (Control Group) Delivery Groups registered for 'Google Groups', which enabled them to communicate and work together on their projects on details with other group members. In the Google Groups environment, students formed their groups, identified other group members, chose a project topic from among those provided by the instructor, and worked collaboratively, sharing their project documents and ideas throughout the semester. 
The instructor followed the same syllabus and content (ppt slides) for both modes (virtual or face-to-face) of student groups, regularly monitored all students' activities through 'Google Groups', and provided them with guidance throughout the semester. Students in the Face-to-face Group (Control Group) attended a course implemented completely on-campus over a 14-week semester. Students in Virtual Group (Experimental Group) followed the course through weekly one-hour-synchronized chat sessions with the instructor. In addition, these students in Virtual Group were able access to the course content via a Learning Management System that allowed them to study asynchronously, that is continuously (24/7).

Both groups of students were assigned a project that involved developing a web-based instructional material teaching one of the areas either suggested by the instructor (e.g. for teaching history, science or math or a foreign language topic, teaching a subjectmatter to K12 kids etc.) or any chosen by themselves.

Groups of students were required to prepare and submit their project proposal and analysis, designdevelopment and implementation-evaluation reports throughout the semester at pre-determined intervals. In the end of the semester, both groups presented their work to a panel of members (instructors and experts in the field of study) in a face-to-face session on campus. Project proposals and reports were collected by the instructor from both virtual and face-to-face groups at pre-planned and pre-announced intervals. The timetable for submissions is given in Table 2.

Table 2. Project Timetable

\begin{tabular}{|c|c|c|c|c|c|c|c|c|c|c|c|c|c|c|}
\hline \multirow{2}{*}{ Course Requirements } & \multicolumn{14}{|c|}{ Weeks } \\
\hline & 1 & 2 & 3 & 4 & 5 & 6 & 7 & 8 & 9 & 10 & 11 & 12 & 13 & 14 \\
\hline Group formation & $x$ & $x$ & & & & & & & & & & & & \\
\hline Project proposal & & & $x$ & & & & & & & & & & & \\
\hline Analysis & & & & & $x$ & & & & & & & & & \\
\hline Design & & & & & & & $x$ & & & & & & & \\
\hline Implementation & & & & & & & & & $x$ & & & & & \\
\hline Evaluation & & & & & & & & & & & & & $x$ & $x$ \\
\hline Trust Development Measurement* & 1. & & & & & & & & & & & & & 2. \\
\hline
\end{tabular}

* Trust scales were released to students for self-administration at the beginning and end of the course.

Students' achievement of the course was determined by evaluating their group project reports, so every student was expected to contribute to the completion of their group project. As indicated in the timetable, both groups were given the same amount of time to prepare and submit their reports for each phase of their projects; thus, participants were expected to spend almost same amount of time on the activities before their trust levels were measured. The maximum scores delievered for each project phase (and for reports) are given in Table 3.

Table 3. Project Evaluation Criteria

\begin{tabular}{lc}
\hline Criteria & Percentage/60 \\
\hline Analysis & 15 \\
Design & 15 \\
Implementation & 15 \\
Evaluation & 15 \\
\hline
\end{tabular}


The reports were considered to represent 60 percent of the total course grade (15\% per report), and a final exam was administered in the end of the semester accounted for the remaining 40 percent. Grades were determined by a panel that included the instructor and additional experts. In order to increase the objectivity of the evaluation, all presentations were videotaped and watched several times by a panel of members before scoring.

\section{Data Collection Instruments}

Trust levels of participants were measured using the trust scale for virtual communities developed by Ridings, Gefen and Arinze (2002). The scale consisted of two dimensions - ability of other members (6 questions) and benevolence/integrity of other members (5 questions) - and allowed participants to assess their peers' ability and benevolence/integrity during the project. In order to measure changes/developments in trust over time, the scales were implemented in Week 1 during the initial meeting and in Week 14 following the final presentation for both delivery modes (Table 2).

The scale was developed during previous semester offer of the same course. The scale was translated into Turkish from the original form which was in English and translated back to English and again Turkish for clarity of understanding. In the next stage, the instrument was delivered to four students who evaluated the instrument for the clarity of language and consistency check between what items tell and what students comprehend. Based on those students' feedback, the instrument was improved. A principal component analysis with varimax rotation was conducted to determine the validity of each of the dimensions of the Turkish version of the scale on the fall semester students of the same course participated in another study. There were 60 students 25 from virtual (10 females) and 35 from face to face class (12 females). KaiserMeyer-Olkin (KMO) Measure of Sampling Adequacy and Bartlett's Sphericity tests were conducted to check whether the data for each dimension was appropriate for factor analysis. To meet the criteria, KMO measures were expected to be higher than .60 (Kaiser, 1974) and Bartlett's test results to be significant (Pett, Lackey, \& Sullivan, 2003). Factor loadings above .320, identified as the threshold for a sufficient and meaningful relation (Tabachnick \& Fidell, 2007), were considered acceptable. Cronbach's a was calculated for each dimension to assess reliability.

KMO \& Barlett's test results for the dimension Ability of other members were .707 and $\mathrm{X}^{2}(28)=212.177$, $\mathrm{p}$ $<.01$, demonstrating that the data satisfied the aforementioned criteria. Principal component analysis found the 6 questions in the Ability dimension explained $79.39 \%$ of total variance, with factor loadings ranging between .815-.932. The Cronbach's a value for the Ability dimension was .95.

KMO \& Barlett's test results for the dimension Benevolence/Integrity of other members were .749 and $\mathrm{X}^{2}$ $(10)=194.105, \mathrm{p}<.01$. Principal component analysis found the 5 questions in the Benevolence/Integrity dimension explained $68.11 \%$ of total variance, with factor loadings ranging between $.726-.900$. The Cronbach's a value for the Benevolence/Integrity dimension was .88.

As indicated by the above measures, both scale dimensions, as well as their individual components, can be considered valid and reliable for measuring the trust of group members.

\section{Data Analysis}

In order to respond the research questions of the study, repeated measures of ANOVA was employed. Field (2005) suggests the use of repeated-measures analysis when the same individuals participate in all stages of an experiment. In the present study, trust variable was measured at the beginning and end of the semester, and the group variable was made up of the delivery types of the course either face to face or virtual.

\section{THE RESULTS}

While the use of repeated measures of ANOVA helps to reduce the unsystematic variability of the study and provides greater power to notice the effects of variables, the "assumption of sphericity" (p. 428), i.e. the similar relationships assumed between pairs of experimental conditions in repeated-measures designs, must 
be checked before interpreting any results in cases where there are more than two repeated measures. Since this study conducted measurements at only two occasions, the assumption of sphericity was not a concern (Field, 2005). As recommended by Field (2005), repeated-measure ANOVA was performed to answer the research questions in the present study. Means and standard deviations for trust measurements are presented in Table 4.

Table 4. Results of repeated-measure ANOVA for Trust

\begin{tabular}{lcccccc}
\hline & \multicolumn{9}{c}{ Delivery Type } \\
\cline { 2 - 8 } Semester Occasions & \multicolumn{3}{c}{ Face to face } & \multicolumn{5}{c}{ Virtual } \\
\cline { 2 - 8 } & 21 & $M$ & $S D$ & 4 & $M$ & .69 \\
\hline In the beginning & 21 & 4.37 & .48 & 43 & 4.23 & .57 \\
\hline In the end & 21 & .56 & 43 & 4.43 & .59 \\
\hline
\end{tabular}

Trust among group members did not demonstrate any significant change between the beginning of the semester $(\mathrm{M}=4.27, \mathrm{SD}=.63)$ and the end of the semester $(\mathrm{M}=4.39, \mathrm{SD}=.56), \mathrm{F}(1,62)=1.649, \mathrm{p}=.204$. Therefore, with regard to Research Question 1, groupwork activities did not seem to influence the degree of trust among group members.

Before analysing Research Question 2, the homogeneity of variance across groups assumption was analysed using Levene's Test of Equality of Error Variances. Levene's tests showed no significant difference in trust measured in the beginning of the semester $[\mathrm{F}(1,62)=1.04, \mathrm{p}=.318]$ or in the end of the semester $[\mathrm{F}(1$, $62)=.001, \mathrm{p}=.982]$. This means that the assumption was not violated. For Research Question 2 , univariate ANOVA test results suggest that course delivery type had no significant effect on average trust levels among group members in the beginning $(M=4.34, S D=.52)$ or in the end of the semester $(M=4.33, S D=.63)$, $\mathrm{F}(1,62)=.002, \mathrm{p}=.962$. These results confirmed that, in answer to Research Question 2, course delivery type did not influence group members' trust in other group members.

With regard to Research Question 3, trust levels of students in both the Face-to-face and Virtual Groups were found to change over time with a medium effect size and sufficient power [Wilk's $\lambda=.924, \mathrm{~F}(1,62)$ $=5.132, \mathrm{p}<.05$, Cohen's $\mathrm{d}=.47 \mathrm{~J}$. Moreover, in the beginning of the semester, trust levels among students in the Face-to-face Group $(\mathrm{M}=4.37, \mathrm{SD}=.48)$ were higher than those in Virtual Group $(\mathrm{M}=4.23, \mathrm{SD}=$ .69). The fact that students in face-to face groups may have had previous contact could explain this finding. However, data collected at the end of the semester indicated that the trust levels of students in the Face-toface Group had decreased $(M=4.31, S D=.56)$, while those in the Virtual Group had increased $(M=4.43$., $\mathrm{SD}=.57$ ) over time. Figure 1 illustrates changes in trust in relation to course delivery type.

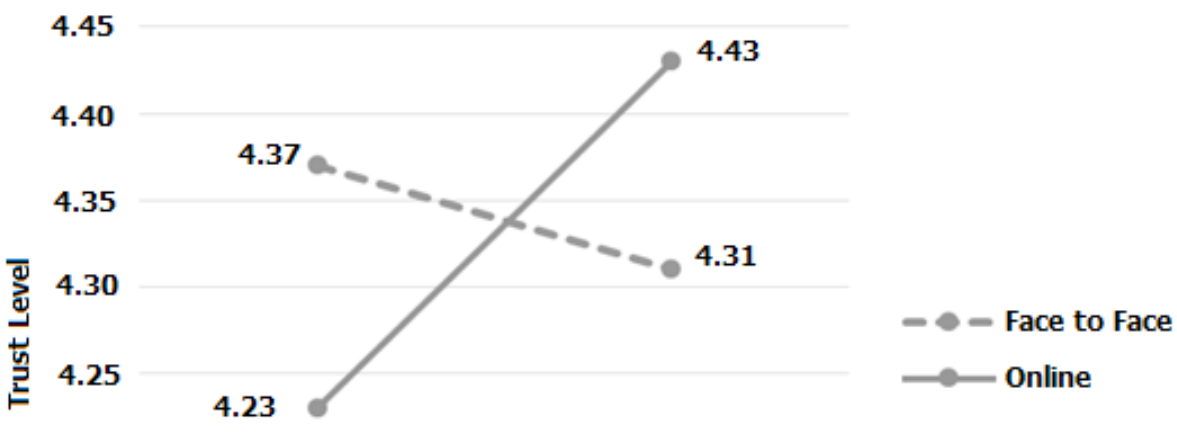

4.20

4.15

4.10

At the Beginning

At the End

Figure 1. Interaction between Trust and Delivery Type 
Given that the interaction between trust and delivery type was found to be significant, repeated measure ANOVA was used to examine the interaction between delivery type and two components of trust, ability and benevolence/integrity of group members, in order to answer Research Question 4. Descriptive results for both components are provided in Table 5 .

Table 5. Results of repeated-measure ANOVA for components of trust

\begin{tabular}{|c|c|c|c|c|c|c|c|c|c|}
\hline \multirow{3}{*}{ Semester Occasions } & \multicolumn{9}{|c|}{ Delivery Type } \\
\hline & \multicolumn{3}{|c|}{ Face to face } & \multicolumn{3}{|c|}{ Virtual } & \multicolumn{3}{|c|}{ Total } \\
\hline & $n$ & $M$ & $S D$ & $n$ & $M$ & $S D$ & $n$ & $M$ & $S D$ \\
\hline \multicolumn{10}{|c|}{ Ability of other Members } \\
\hline At the beginning & 21 & 4.29 & .50 & 43 & 4.26 & .77 & 64 & 4.27 & .70 \\
\hline At the end & 21 & 4.35 & .55 & 43 & 4.40 & 64 & 64 & 4.38 & .61 \\
\hline \multicolumn{10}{|c|}{ Benevolence/Integrity of other Members } \\
\hline At the beginning & 21 & 4.44 & .57 & 43 & 4.20 & .71 & 64 & 4.28 & .67 \\
\hline At the end & 21 & 4.27 & .65 & 43 & 4.47 & .55 & 64 & 4.40 & .58 \\
\hline
\end{tabular}

The interaction between group-member ability and course delivery-type was not found to be significant [Wilk's $\lambda=.994, \mathrm{~F}(1,62)=.356, \mathrm{p}=.553]$. In contrast, the interaction between group-member benevolence/ integrity and course-delivery type was found to be significant with close to high effect size [Wilk's $\lambda=.861, \mathrm{~F}$ $(1,62)=10.026, \mathrm{p}<.01$, Cohen's $\mathrm{d}=.70]$. Thus, the findings related to building overall trust among group members engaged in an educational project can be attributed mainly to the benevolence/integrity of other group members, not their ability.

\section{DISCUSSION}

According to the study results, while the levels of trust among group members did not vary significantly between Face-to-face and Virtual groups in the end of the semester, the change in trust levels over the course of the semester did vary significantly according to the mode of course delivery. These results might provide a general understanding about how trust develops in groups of students in virtual and face-to-face collaborative learning environments.

The existence of effective communication among groupmates has been shown to have a positive effect on the development of trust, with virtual groups said to be capable of developing better flow of communication and more casual communication than traditional groups (Martins, Gilson \& Maynard, 2004). In this study, although the level of trust among students in Face-to-face group was higher than that of students in Virtual Group in the beginning of the semester; this situation reversed itself by the end of the semester. It is probable that the increase in trust among virtual students was due in part to their needs of and efforts for communicating more effectively in their limited interaction time. Besides, these students may have benefitted more from the 'Google Groups' platform compared to Face-to-face group ones. Their limited interaction may have also enforced virtual students to work more eagerly on group tasks; which could be further investigated in additional studies.

It is also likely that face-to-face group students previously came into contact with each other through other courses in the graduate program, whereas virtual students did not have a chance to meet previously for any schoolwork and thus did not have a chance to build trust. This could explain why trust level of virtual students was lower than that of face-to-face students in the beginning of the semester. The increase in trust levels towards the end of the semester among virtual students would be supported by Ridings, Gefen and Arinze's (2002) suggestion that "the importance of trust in co-located workgroups may be somewhat different from trust in virtual organizations and societies where people may never actually meet in person" (p. 275). According to Handy (1995), face-to-face communication, which is the most effective means of generating trust, is easy for local members; whereas, building trust in a virtual environment is problematic 
because team members usually have no common past and/or have not previously met face-to-face (Lin, Standing \& Liu, 2008). This indicates that effective communication, particularly during the early stages of a group's development, plays a crucial role in gaining and maintaining trust (Anderson, McEwan, Bal \& Carletta, 2007).

Gerdes (2010) states that computer-mediated communication implies greater uncertainty compared to faceto-face communication. Given that developing trust requires time, it is likely that virtual participants in this study were only able to build and develop trust towards the end of the semester, that is, after they had performed certain collaborative activities. A study examining the effects of communication opportunities in different mode groups (Bos, Olson, Gergle, Olson \& Wright, 2002) asserted that face-to-face groups develop trust faster than virtual groups. Similarly, in the current study, face-to-face students seemed to develop trust earlier than virtual students; however, by the end of the semester, the level of trust became lower in comparison to virtual students. A recent meta-analysis related to trust development in virtual teams (Mitchell \& Zigurs, 2009) discussed the need for addressing the relationship between time and trust in virtual teams in diverse contexts. The results of the present study indicate that trust can develop over time with effective communication and that virtual learners are able to understand each other' insights more clearly and trust each other more with the passage of time. The study was conducted over a 14-week semester in which the trust of students was measured first during the 1 st week and again during the final week. The results point out that the time required for effective trust development is another significant issue to be investigated in further detail. While the current study provides an overall idea regarding the issue of time in the development of trust among group members, whether the amount of trust acquired changes with respect to the number of tasks, deadline or work-load are other issues worthy of investigation.

\section{CONCLUSION}

This study examined how trust develops during virtual collaborative learning activities and compared this with development of trust in a face-to-face collaborative learning environment. The results demonstrated that trust increased over time among virtual participants, but declined among face-to-face participants; moreover, trust levels were strongly affected by the benevolence/integrity, but not by the ability of other group members.

This study was limited to its use of a quasi-experimental nonequivalent group comparison design (Johnson \& Christensen, 2008), which has the potential for selection bias, since groups were not randomly assigned. In order to control the selection bias, trust was measured at two different occasions. The first measurement was performed in the beginning of the semester which was considered a 'pretest' to control for existing significant differences in trust levels that might have resulted from probable previous interaction among members in the face-to-face group. Another study limitation was concerned with selection maturation, i.e. one group may have had more experience than the other group regarding trust development; however, given similar demographic characteristics of the participants, it is hardly possible to occur with this regard. Finally, selection-regression, i.e. differences in the populations of the two groups, was another study limitation. Although the study included participants from a variety of professions, these were distributed heterogeneously between two groups.

In order to minimize the mentioned limitations and obtain more robust results, further studies that apply true-experimental models may be carried out. Moreover, given that the present study did not consider any confounding factors during the development of trust, further research regarding any confounding factors that might affect the process of trust development is strongly recommended. Other topics of future research might include the relation between trust and other groupwork outcomes, such as task accomplishment, number of tasks completed and group performance. Finally, the effects of initial group trust, time spent on collaborative work and task type on the development of trust over time are also worth examining. This accumulated evidence-based knowledge can be used to support instructors teaching in collaborative groups. 


\section{BIODATA and CONTACT ADDRESSES of AUTHORS}

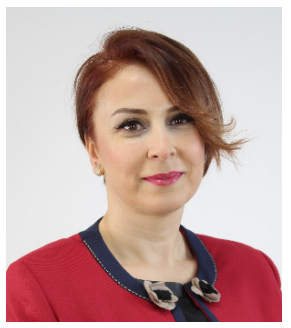

Dr. Meltem Huri BATURAY, is a professor of Instructional Technology at the Department of Basic English, Foreign Languages School, Atilim University. Dr. Baturay gained her Ph.D. in Instructional Technology at September, 2007. Her academic interest areas are instructional design, web-based language education, computerassisted language teaching, e-learning, application of different methods in distance education, MOOCs and use of social media in education. She has over than 25 journal articles published in international indexes, 1 international book, 3 international book chapters and other national and international articles, papers submitted to international meetings. She also worked as a researcher in TUBITAK (The Scientific and Technological Research Council of Turkey) and Erasmus+ projects. Baturay is experienced in multimedia supported and video-based training materials development.

Meltem Huri BATURAY

Address: Department of Basic English, School of Foreign Languages

Atilim University, 06830, Incek, Ankara, TURKEY

Phone: +90 3125868500

E-mail: meltem.baturay@atilim.edu.tr

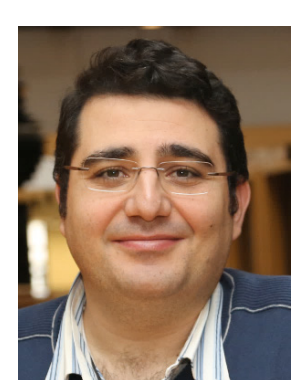

Dr. Sacip TOKER, received the B.S. degree in computer education and M.S. degree in educational sciences from Middle East Technical University, Ankara, Turkey, in 2001 and 2004 respectively, and the Ph.D. degree in instructional technology from Wayne State University, Detroit, MI, USA in 2012. He was a Researcher with Capital Analytics, Dunham, NC between 2011 and 2012. He was an Assistant Professor at Computer Education and Instructional Technology Department, College of Education, Mehmet Akif Ersoy University, Burdur, Turkey. He has been working as an Assistant Professor at Information Systems Engineering Department, College of Engineering, Atilim University, Ankara, Turkey since 2018. He had several journal and book chapter publications. He worked as a research in a TUBITAK (The Scientific and Technological Research Council of Turkey) projects. He was a member of winner team at 3rd Annual University Case Study Competition sponsored by International Society for Performance Improvement, Silver Spring, MD in 2011. His works appeared in a number of professional journals and books.

\section{Sacip TOKER}

Address: Department of Information Systems Engineering, School of Engineering

Atilim University, 06830, Incek, Ankara, TURKEY

Phone: +90 3125868340

E-mail: sacip.toker@atilim.edu.tr

\section{REFERENCES}

Anderson, A. H., McEwan, R., Bal, J., \& Carletta, J. (2007). Virtual team meetings: An analysis of communication and context. Computers in Human Behavior, 23, 2558-2580.

Bos, N., Olson, J., Gergle, D., Olson, G., \& Wright, Z. (2002). Effects of four computer-mediated communications channels on trust development. Proc. CHI 2002, ACM Press, pp. 135-140.

Cheng, X., Nolan, T., \& Macaulay, L. (2013). Don't give up the community: a viewpoint of trust development in online collaboration. Information Technology \& People, 26(3), 298-318.

Coppola, N.W., Hiltz, S.R \& Rotter, N. (2004). Building trust in virtual teams. IEEE Transactions on Professional Communication, 4, $95-104$.

Crossman, A., \& Lee-Kelley, L. (2004). Trust, commitment and team working: The paradox of virtual organizations. Global Networks, 4 (4), 375-390. 
Crowe, P., Collins, M., Larue, O., Green, R., Hough, A., \& Juvina, I. (2017, September). Examining the Role of Trust in Peer-Assisted Learning. In Proceedings of the Human Factors and Ergonomics Society Annual Meeting (Vol. 61, No. 1, pp. 165-169). Sage CA: Los Angeles, CA: SAGE Publications.

De Meo, P., Messina, F., Rosaci, D., \& Sarné, G. M. (2017). Combining trust and skills evaluation to form e-Learning classes in online social networks. Information Sciences, 405, 107-122.

Field, A. (2005). Discovering Statistics Using SPSS: And Sex, Drugs, and Rock'n' Roll (2nd ed.). Sage Publications: London.

Fraenkel, J. R., \& Wallen, N. E. (2000). How to design and evaluate research in education New York: McGraw.

Fransen, J. Kirschner, P.A. \& Erkens, G. (2011). Mediating team effectiveness in the context of collaborative learning: The importance of team and task awareness. Computers in Human Behavior 27(3): 11031113.

Fransen, J., Weinberger, A., \& Kirschner, P. (2013). Team effectiveness and team development in CSCL. Educational Psychologist, 48, 9-24.

Gerdes, A. (2010). Revealing preconditions for trustful collaboration in CSCL. Computer-Supported Collaborative Learning, 5, 345-353.

Handy, C. (1995). Trust and the virtual organization. Harvard Business Review, 73, 40-50.

Isohätälä, J., Järvenoja, H., \& Järvelä, S. (2017). Socially shared regulation of learning and participation in social interaction in collaborative learning. International Journal of Educational Research, 81, 11-24.

Jannsen, J., Erkens, G. \& Kirschner, P. A. (2010). Group awareness tools: It's what you do with it that matters. Computers in Human Behavior, 27(3), 1046-1058.

Johnson, B. \& Christensen, L. (2008). Educational Research: Quantitative, Qualitative, and Mixed Approaches (3rd ed.) Sage Publications: Los Angeles.

Kaiser, H. (1974). An index of factorial simplicity. Psychometrika, 39(1), 31-36. doi: 10.1007/bf02291575

Kiffin-Petersen, S. A. (2004). Trust: A neglected variable in team effectiveness research. Journal of the Australian and New Zealand Academy of Management, 10(1), 38-53.

Leroy, L., Rittner, J. L., Johnson, K. E., Gerteis, J., \& Miller, T. (2017). Facilitative Components of Collaborative Learning: A Review of Nine Health Research Networks. Healthcare Policy, 12(3), 19-33.

Lin, C., Standing, C., \& Liu, Y. (2008). A model to develop effective virtual teams, Decision Support Systems, 45(4), 1031-1045.

Liu, X., Magjuka, R. J. \& Lee, S. (2008). An examination of the relationship among structure, trust, and conflict management styles in virtual teams. Performance Improvement Quarterly, 21: 77-93

Martins, L.L., Gilson, L.L., \& Maynard, M.T. (2004). Virtual teams: What do we know and where do we go from here? Journal of Management, 30(6): 805-835.

Mitchell, A., \& Zigurs, I. (2009). Trust in virtual teams: Solved or still a mystery? Data Base for Advances in Information Systems, 40(3), 61-83.

Nandhakumar, J., \& Baskerville, R. (2006). Durability of online teamworking: patterns of trust. Information Technology \& People, 19(4), 371-389.

Ocker, R. J., \& Fjermestad, J. (2008). Communication differences in virtual design teams: findings from a multi-method analysis of high and low performing experimental teams. The DATA BASE for Advances in Information Systems, 39(1), 51-67.

Panteli, N., \& Duncan, E. (2004). Trust and temporary virtual teams: alternative explanations and dramaturgical relationships. Information Technology \& People, 17(4), 423-441.

Phielix, C., Prins, F. J., Kirschner, P. A., Erkens, G., \& Jaspers, J. (2010). Group awareness of social and cognitive performance in a CSCL environment: Effects of a peer feedback and reflection tool. Computers in Human Behavior, 27(3), 1087-1102. 
Pett, M. A., Lackey, N. R., \& Sullivan, J. J. (2003). Making sense of factor analysis: The use of factor analysis for instrument development in health care research. Thousand Oaks, CA: SAGE.

Ridings, C. M., Gefen, D., \& Arinze, B. (2002). Some antecedents and effects of trust in virtual communities. The Journal of Strategic Information Systems, 11(3-4), 271-295.

Salomon, G., \& Globerson, T. (1989). When teams do not function the way they ought to. International Journal of Educational Research, 13, 89-99.

Sangin, M., Molinari, G., Nussli, M.-A. \& Dillenbourg, P. (2010) Facilitating peer knowledge modeling: effects of a knowledge awareness tool on collaborative learning outcomes and processes. Computers in Human Behavior, 27(3), 1059-1067.

Serva, M., \& Fuller, M. (2004). Aligning what we do and what we measure in business schools: Incorporating active learning and effective media use in the assessment of instruction. Journal of Management Education, 28(1), 19-38

Stacey, E. (2002). Learning links online: Establishing constructivist and collaborative learning environments. Paper presented at the Untangling the Web: Establishing Learning Links, Melbourne. http://dro. deakin.edu.au/eserv/DU:30004665/stacey-learninglinksonline-2002.pdf

Staples, D. S. \& Webster, J. (2008). Exploring the effects of trust, task interdependence and virtualness on knowledge sharing in teams. Information Systems Journal, 18: 617-640.

Tabachnick, B. G., \& Fidell, L. S. (2007). Using Multivariate Statistics (5th ed.). Boston, MA: Pearson Education. Inc.

Tseng, H. (2008). The relationships between trust and satisfaction and performance among the virtual teams with different developmental processes, Unpublished Ph.D. Dissertation, University of Northern Colorado

West, M. A. \& Wallace, M. (1988). Innovations in Primary Health Care Teams: The Effects Roles and Climates, Conference Paper Presented in Annual Conference of the British Psychological Society at University of Manchester, Manchester.

Williams, E. A., Duray, R. \& Reddy, V. (2006). Teamwork orientation, group cohesiveness, and student learning: a study of the use of teams in online distance education. Journal of Management Education, 30(4): 592-616.

Wilson, J.M., Straus, S.G. \& McEvily, W.J. (2006(. All in due time: The development of trust in computermediated and face-to-face groups. Organizational Behavior and Human Decision Processes, 99, 16-33.

Van Gennip, N.A.E., Segers, M.S.R., \& Tillema, H.H. (2010). Peer assessment as a collaborative learning activity: The role of interpersonal variables and conceptions. Learning and Instruction, 20, 280-290

Vygotsky, L. S. (1978). Mind and society: The development of higher mental processes. Cambridge, MA: Harvard University Press. 